\title{
FRAX and Exercise: Should Exercise Be Categorized as a Risk Factor in Osteoporotic Patients
}

\author{
Akira Horikawa $^{1}$, Naohisa Miyakoshi ${ }^{2}$, Yoichi Shimada ${ }^{2}$, Hiroyuki Kodama ${ }^{1}$ \\ ${ }^{1}$ South Akita Orthopedic Clinic, Katagami, Japan; ${ }^{2}$ Department of Orthopedic Surgery, Akita University Graduate School of Medi- \\ cine, Akita, Japan. \\ Email: akiraellen@me.com
}

Received March 23 $3^{\text {rd }}, 2013$; revised May $4^{\text {th }}, 2013$; accepted May 21 ${ }^{\text {st }}, 2013$

Copyright (C) 2013 Akira Horikawa et al. This is an open access article distributed under the Creative Commons Attribution License, which permits unrestricted use, distribution, and reproduction in any medium, provided the original work is properly cited.

\begin{abstract}
Although FRAX (WHO Fracture Risk assessment Tool), developed by the WHO, is a well-validated tool for determining the probability of a major osteoporotic fracture in the next 10 years, it doesn't include a number of other impact factors such as exercise and nutrition. The purpose of this study was to compare the differences in FRAX between subjects with and without exercise habits or intake of calcium/coffee. A significant difference in FRAX was observed between the groups with respect to exercise $(p<0.001)$. There were no significant differences in FRAX, however, between the groups with and without intake of calcium/coffee. Although exercise habits are not included in FRAX, our findings suggest that exercise status influenced other factors included in FRAX. Since exercise is reported to prevent falls and fall-related osteoporotic fractures, including exercise status in FRAX may be more effective for estimating the possibility of future fractures. Further investigation should be conducted to determine whether exercise status is an important risk factor, independent of FRAX, for osteoporotic fractures.
\end{abstract}

Keywords: FRAX; Exercise; Osteoporosis

\section{Introduction}

FRAX is an algorithm-based computer program that utilizes risk factors, along with bone mineral density (BMD) to predict the absolute percentage of risk for a major osteoporotic fracture over the next 10 years. The FRAX tool, a result of the concerted efforts of multiple meta-analyses utilizing 12 different prospective studies with representation from Europe, Australia, Finland, Japan, France, Sweden, and USA, was developed by the WHO (WHO Fracture Risk Assessment Tool) [1]. Risk factors included in FRAX are 1) age; 2) gender; 3) smoking; 4) three or more alcoholic drinks per day; 5) parent with a hip fracture; 6) rheumatoid arthritis; 7) low body mass index (BMI); 8) prolonged glucocorticoid exposure; 9) secondary osteoporosis; and 10) BMD [2].

Other risk factors for fractures, such as activity level (exercise), which have the positive benefits of improving mechanical balance and stability to reduce the likelihood of falls [2], risk of falls which strongly predict hip and other non-vertebral fracture regardless of intrinsic skeletal strength [3], and nutrition (calcium, Vitamin D, and caffeine intake which contribute to improved BMD and the prevention of fractures) [4], however, are not included in FRAX. The purpose of this study was to evaluate other valid risk factors including exercise and nutriation, along with BMD and FRAX.

\section{Participants}

A total of 156 consecutive Japanese women who had visited the first author's orthopedic clinic between January 2010 and September 2011 and had a femoral neck or lumbar spine BMD value less than 2.5 SDs lower than the reference values were enrolled in this study. Among these women, 56 subjects with acute or chronic illness other than osteoporosis, malignant neoplasm, use of walking aid devices other than a cane, and dementia, were excluded (Figure 1). The 100 remaining patients eligible for the study received a questionnaire relating to habitual lifestyle including exercise habits, daily activity, dietary habits including intake of foods rich in calcium and favorable foods such as coffee, and risk factors that are currently acknowledged by FRAX. Written informed consent was obtained from all participants at the begining of the study. 


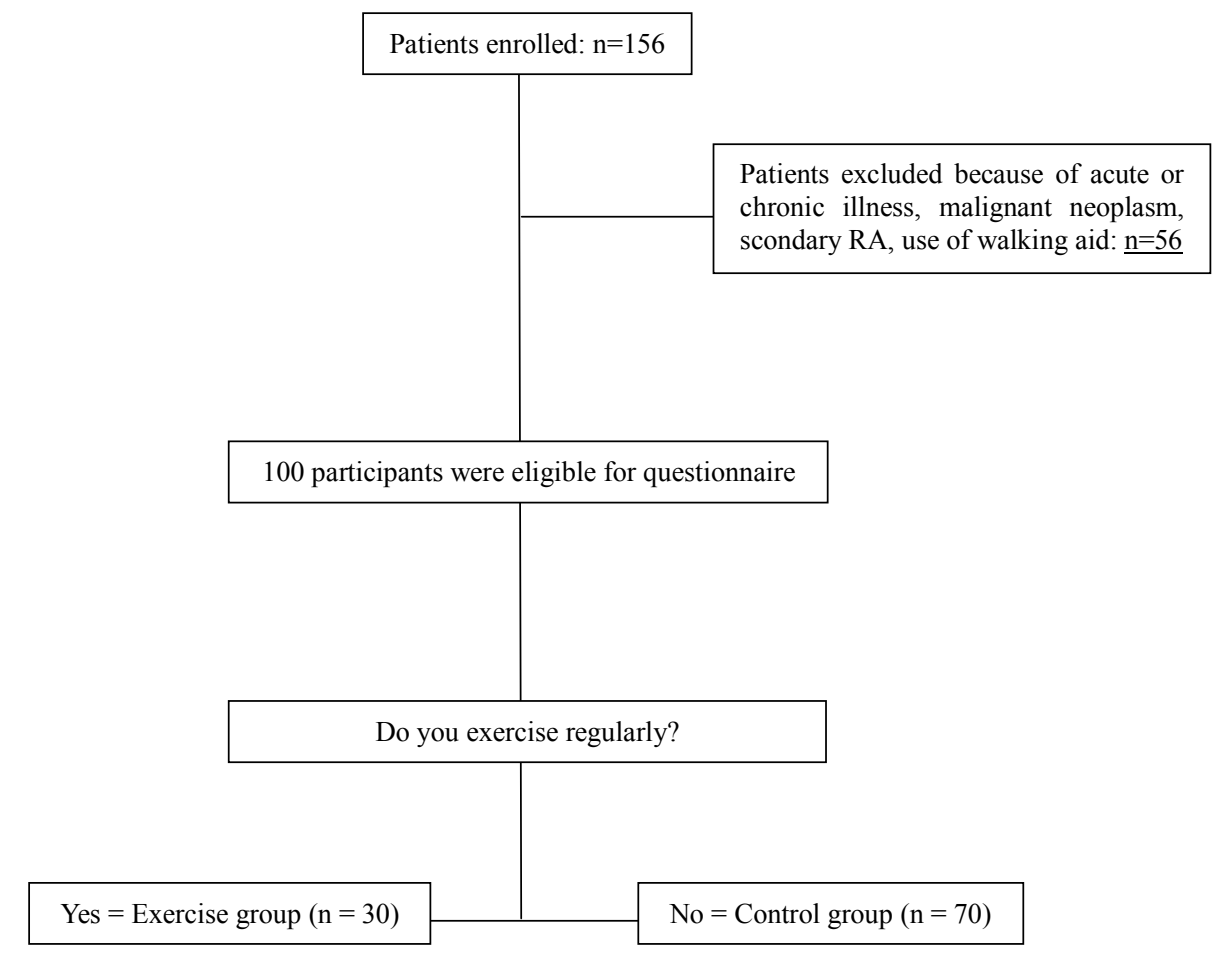

Figure 1. The process of study selection. Data on age, height, weight, BMI, nutritional lifestyle (calcium, coffee) and lifestyle habits (smoking, alcohol) were collected from all participants.

\subsection{Bone Measurements}

Areal BMD measurements were performed at the proximal femur and lumbar spine using dual energy X-ray absorptiometry (Hologic QDR Discovery W type, Toyo Medic., Japan)

\subsection{Statistical Analysis}

Statistical analysis was performed using the Microsoft Office Excel application and the Statcel 3 program (OMS, Inc., Japan). Fracture risk was calculated for each subject, according to the FRAX algorithm to compare differences between the two groups. For the dichotomous variables, the Chi-square test was used to evaluate the significance of the differences. Single factor ANOVA and a post hoc test (Fisher's Protected Least Significant Difference) were used to compare differences between four study groups created based on a combination of exercise and calcium intake. All the results of statistical tests were regarded as statistically significant when $p<0.05$.

\section{Results}

Data from the exercise and control groups are shown in Table 1. There were 30 women in the exercise group and 70 in the control. There were no significant differences in age and BMI between the exercise and control groups; but significant differences in FRAX were detected. According to our data from FRAX analysis, there was no statistical difference in FRAX between individuals who took calcium supplements and coffee (Figure 2). There was, however, a statistically significant difference in FRAX between the exercise group and control group, regardless of whether they took calcium supplements (Figure 3).

\section{Discussion}

Although FRAX, developed by the WHO, is considered a well-validated tool for determining the probability rate of a major osteoporotic fracture or hip fracture in the next 10 years, it may lack other important risk factors. A number of researchers have suggested the importance of life style modification that includes measures to reduce risk of falls and bone loss, such as exercise, adequate dietary calcium and avoidance of smoking and excessive alcohol consumption $[5,6]$. Although there are some reports on the effectiveness of exercise for the prevention of fractures $[7,8]$, we found a few studies showing that physical therapy influences FRAX analysis $[2,3,6]$. Physical therapy may interfere with falling $[8,9]$, and presumably reduce the probability of fracture based on FRAX. The results from the present study indicate that compared to women who do not exercise, women who exercise regularly have a lower risk of femoral neck fracture. These findings suggest that exercise status influences other factors included in FRAX. Since exercise is reported to prevent falls and fall-related osteoporotic 
Table 1. Comparison of variables in the exercise and control groups.

\begin{tabular}{lccc}
\hline & Exercise group $(\mathrm{n}=30)$ & Control group $(\mathrm{n}=70)$ & p-value \\
\hline Age (years) & $66.9 \pm 7.9$ & $74.8 \pm 6.4$ & $0.20^{\mathrm{a}}$ \\
Height $(\mathrm{cm})$ & $152 \pm 5.2$ & $149 \pm 5.1$ & $0.01^{\mathrm{a}}$ \\
Weight $(\mathrm{kg})$ & $55.8 \pm 9.9$ & $51.2 \pm 8.6$ & $0.02^{\mathrm{a}}$ \\
BMI $\left(\mathrm{kg} / \mathrm{m}^{2}\right)$ & $24 \pm 4.0$ & $23.1 \pm 3.6$ & $0.20^{\mathrm{a}}$ \\
FRAX $(\%)$ & $3.6 \pm 0.6$ & $8.7 \pm 0.7$ & $<0.001^{\mathrm{a}}$ \\
Alcohol (n) & 2.0 & 3.0 & $0.62^{\mathrm{b}}$ \\
Smoking (n) & 1.0 & 1.0 & $0.53^{\mathrm{b}}$ \\
\hline
\end{tabular}

${ }^{a}$ Student's t-test; ${ }^{\text {b }}{ }^{2}$ test.

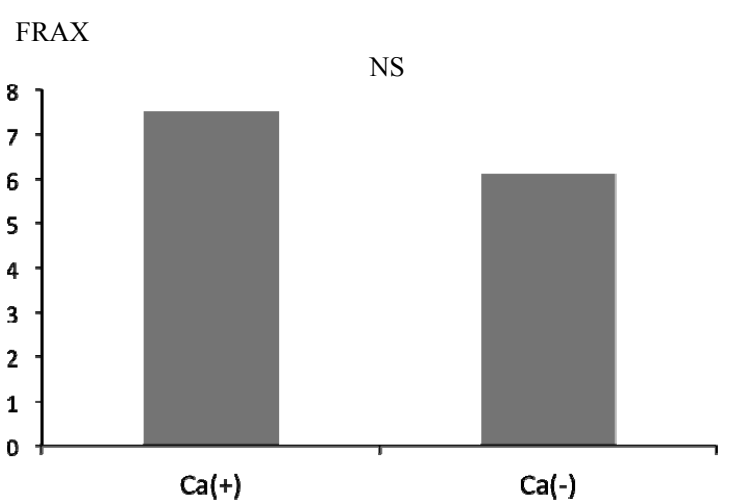

(a)

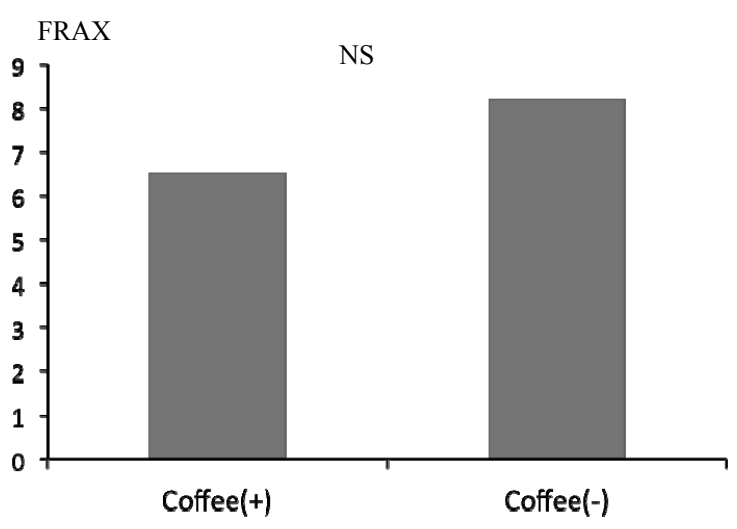

(b)

Figure 2. Statistical analysis of FRAX score between nutrition groups (Student-t test). (a) Comparison between the groups with and without calcium (Ca) supplements; (b) Comparison between the groups with and without coffee.

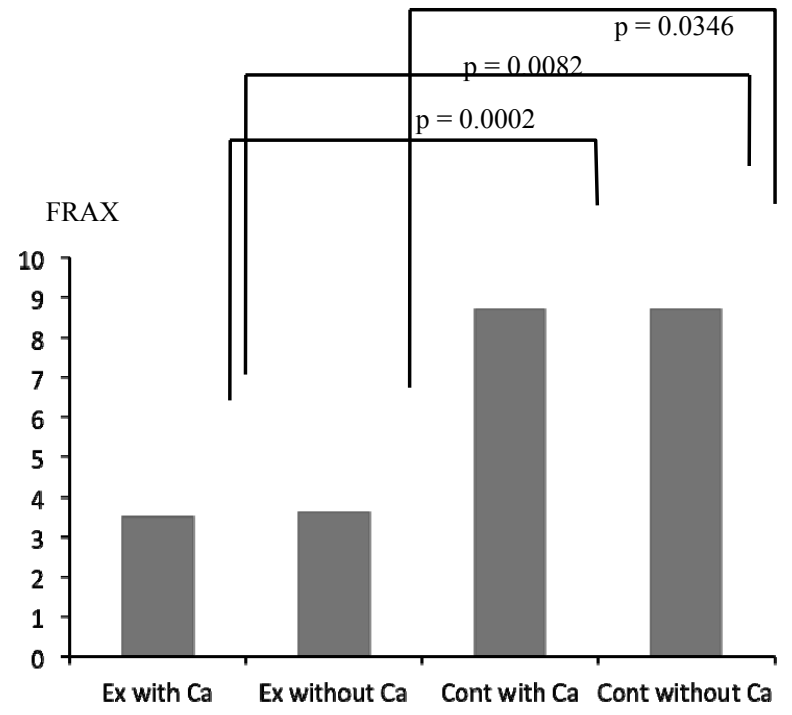

Figure 3. Statistical analysis of FRAX score among the groups with a combination of exercise (Ex) and calcium (Ca) intake (single factor ANOVA and a post hoc test). Cont = control.

fractures, including exercise status in FRAX may be more effective for estimating the possibility of future fractures.
Based on data from the present study, individuals who have a habit of regular exercise can reduce the possibility rate of osteoporotic fracture in the future. We also assessed nutritional status with relation to calcium intake and coffee because these are factors that can be easily measured, similar to alcohol and smoking habits that are included in the present version of FRAX [2]. Contrary to our expected results, we found no significant impact of these nutritional factors on risk of osteoporotic fracture.

In addition, Honig [4] and McCloskey [5] reported that the combination of regular exercise with calcium intake can reduce the risk of osteoporotic fracture. However, using only the FRAX tool, we did not detect significant differences in fracture risk with the combination of exercise and calcium intake in the present study. The percentage of FRAX observed in the present study is lower than the cut-off point of FRAX (15\%) used to initiate osteoporosis treatment that is recommended by the Japanese guideline for the prevention and treatment of osteoporosis (year 2011 version) [10]. This may reflect the fact that the patients in our study had relatively mild (not severe) osteoporosis. The average BMD of our study participants was $-3.0 \mathrm{SD}$ whereas the average BMD reported by the database of Japanese osteoporosis was -2.64 and FRAX (femur) was 8.8\% [11]. These results 
are very similar to our data in the non-exercise controls.

The analyses by Karinkanta et al. [8] and Sherrington et al. [9] indicate that exercise programs can reduce fall rates in elderly individuals, which implies that the FRAX algorithm should take into consideration exercise habits and falls as risk factors [12]. They also emphasized the importance of physically challenging balance training and a high amount and frequency of exercise and did not recommend a walking-only program. Our findings from the current study, using FRAX, indicate that the exercise group had a significantly lower possibility of fracture compared to the control group due to highly-active agricultural work. Although our data suggest that exercise should be promoted as a risk factor to be included in FRAX, other risk factors, such as history of falling and use of walking aids, should also be considered [13].

In summary, we evaluated the relationship between risk factors and exercise using the FRAX tool in osteoporotic patients. A regular habit of exercise decreased the prediction rates of risk of fracture using FRAX although there was negative impact about nutrition factor. Other risk factors for osteoporotic fracture, such as exercise and falling, should therefore be considered when using FRAX.

\section{Acknowledgements}

This study was supported by the South Akita Orthopedic Clinic. The authors declare that they did not receive funds from any hospital and did not pay gratuities to patients.

\section{REFERENCES}

[1] World Health Organization, "WHO Scientific Group on the Assessment of Osteoporosis at Primary Health Care Level," Summary Meeting Report, Brussels, May 2004, pp. 5-7.

[2] D. L. Dunniway, B. Camune, K. Baldwin and J. K.Crane, "FRAX ${ }^{\circledR}$ Counseling for Bone Health Behavior Change in Women 50 Years of Age and Older," Journal of the American Academy of Nurse Practitioners, Vol. 24, No. 6, 2012, pp. 382-389. doi:10.1111/j.1745-7599.2012.00700.x

[3] D. C. Bauer, "FRAX, Falls, and Fracture Prediction. Predicting the Future," Archives of Internal Medicine, Vol.
171, No. 18, 2011, pp. 1661-1662. doi:10.1001/archinternmed.2011.495

[4] S. Honig, "Treatment Strategies for Patients with Low Bone Mass: The Younger Postmenopausal Female," Bulletin of the NYU Hospital for Joint Diseases, Vol. 66, No. 3, 2008, pp. 240-243.

[5] E. McCloskey, "Preventing Osteoporotic Fractures in Older People," Practioner, Vol. 255, No. 1736, 2011, pp. 19-22.

[6] S. B. Perry and P. A. Downey, "Fracture Risk and Prevention: A Multidimensional Approach," Physical Therapy, Vol. 92, No. 1, 2012, pp. 164-178. doi: $10.2522 / \mathrm{ptj} .20100383$

[7] R. Korpelainen, "Long-Term Outcomes of Exercise: Follow-Up of a Randomized Trial in Older Women with Osteopenia," Archives of Internal Medicine, Vol. 170, No. 17, 2010, pp. 1548-1556.

doi:10.1001/archinternmed.2010.311

[8] S. Karinkanta, M. Piirtola, H. Sievänen, K. Uusi-Rasi and P. Kannus, "Physical Therapy Approaches to Reduce Fall and Fracture Risk among Older Adults," Nature Reviews Endocrinology, Vol. 6, No. 7, 2010, pp. 396-407. doi:10.1038/nrendo.2010.70

[9] C. Sherrington, J. C. Whitney, S. R. Lord, R. D. Herbert, R. G. Cumming and J. C. Close, "Effective Exercise for the Prevention of Falls: A Systematic Review and MetaAnalysis," Journal of the American Geriatrics Society, Vol. 56, No. 12, 2008, pp. 2234-2243. doi:10.1111/j.1532-5415.2008.02014.x

[10] O. Sigeru (Japanese Osteoporosis Foundation), "Baseline of Starting for Medical Treatment of Osteoporosis," Japanese Guideline for the Prevention and Treatment of Osteoporosis, Life Science, Tokyo, 2011.

[11] H. Takayuki (Japanese Osteoporosis Foundation), “Osteoporotic Management for the Effective Prevention of Elderly Care. The Business of Promotion of Senile Insurance Health Year," 2009.

[12] B. Abrahamsen, "FRAX in Clinical Practice," Nature Reviews Rheumatology, Vol. 7, No. 12, 2011, pp. 686-688. doi:10.1038/nrrheum.2011.155

[13] A. W. Kung, K. K. Lee, A. Y. Ho, G. Tang and K. D. Luk, "Ten-Year Risk of Osteoporotic Fractures in Postmenopausal Chinese Women According to Clinical Risk Factors and BMD T-Scores: A Prospective Study," Journal of Bone and Mineral Metabolism, Vol. 22, 2007, pp. 10801087. doi:10.1359/jbmr.070320. 